\title{
H. B. SMITHER
}

Herbert Buxton Smither died on 27 October 1937 at the age of 56. After leaving school he worked for several years with the University Life Assurance Society and obtained his Fellowship of the Institute in 1919. During I924 he had a severe illness, now thought to have been caused by typhoid in youth, and it was necessary for him to have both legs amputated. As a consequence, he had to give up office work at the " University", where he was, perhaps, never wholeheartedly content, and the rest of his life was spent in miscellaneous actuarial work-a little consulting work, calculations for brother actuaries and, most happily of all, on the continuous mortality investigation. Readers of the Journal will remember notes by Smither on Generation Tables, some tables based on the Eastern Counties Rural Districts Male Mortality 1920-22, many reviews and his share in the notices of Foreign Journals and in a recent paper on Light and Heavy Mortality. Smither's share in joint work was a lion's share until publication when he was unwilling to be credited with any share at all.

It is hard to describe to those who have not been closely in touch with the mortality investigation how much of the recent work has come from his suggestions: practically everything for the past few years has been done under his supervision. There are still available many pages of his notes for consideration and when the further study of the annuity experience is published it will be based on his thoughtful work.

Todhunter, speaking to me some years ago, summed Smither up by saying that, in contrast with some other actuaries, he had an "actuarial conscience"! This conscience was exemplified in the mortality work by his quiet refusal to accept any method, or any explanation of the statistics, or any statement or return till he was satisfied with it: this attitude, combined with a readiness to take over any awkward task, with his fund of helpful suggestions, his sympathetic criticism and friendliness, made Smither the ideal colleague in such an investigation. His keenness made us forget that he was never really well and that his life was a perpetual struggle against great physical discomfort and uncertain health. Yet whenever he came to talk over difficulties or some big piece of work he left behind an impression of cheerful companionship-one had a feeling of gratitude that he had come-and that remains.

W. P. E. 